\title{
Multiobjective optimization of low-rigidity corrosion-resistant steel parts grinding considering error standards
}

\author{
Soler Yakov Iosifovich \\ Irkutsk National Research Technical University \\ Irkutsk, Russian Federation, 664074, Lermontova St., 83 \\ e-mail: solera@istu.irk.ru
}

\author{
Strelkov Aleksey Borisovich \\ Irkutsk National Research Technical University \\ Irkutsk, Russian Federation, 664074, Lermontova St., 83 \\ e-mail: AlexejST@gmail.com
}

\begin{abstract}
The results of the research are concerned with multiobjective optimization of low-rigidity corrosion-resistant steel parts grinding, based on the models of multivariate dispersion analysis with error standards minimization.
\end{abstract}

Keywords-robust design, error standard, CBN grinding, surface condition, roughness, multistep grinding, multiobjective optimization

\section{INTRODUCTION}

At present, a new concept, known as a «robust design approach» $[1,2]$, reducing process engineering timescales, is intensively being developed. This concept includes three stages: system design (quality control at process design); parametric design (production quality control) and quality design. In the process of robust design, the importance of parts quality assurance is transferred from the second stage to the first one. This decreases fabrication manufacturing work content and increases its competitiveness in the market economy environment. However, the control is not so much developed at the stage of design compared to that of manufacturing and demands some additional research in every particular case. In this paper, one of the stages of the concept is implemented for surface grinding using microrelief criteria and form accuracy with error standards minimization.

To fabricate critical high load parts of airborne vehicles, subjected to atmospheric forcing in the course of maintenance, high-resistance noncorrosive steels such as 13X15H4AM3: $\sigma_{\mathrm{B}}=1390-1650 \mathrm{MPA}, \delta=15 \%, \mathrm{E}=220 \mathrm{MPa}$ are widely used. The last one is related to transient austenitic-martensitic steels. Surface grinding is extensively used at the final parts fabrication stage. The rigidity component spectrum of ground parts is manifold. There are low-rigidity billets, which are very compliant $[3,4]$. However, this is often neglected without due attention. The discussed steels have low grinding properties; that is why $\mathrm{CBN}$ grinding wheels have been applied.

The traditional methods of experimental detection of optimum function of several variables of $y=f(A, B, C, D, \ldots, Z)$ introduce a successive analysis of partial dependence, as follows: $-\mathrm{y}=\mathrm{f}(\mathrm{A}), \mathrm{y}=\mathrm{f}(\mathrm{B})$. The disadvantage of this approach is in the fact that it is impossible to take account of factor interaction. Some complex factors are simultaneously used and do not permit to vary the importance of separate output parameters considering process requirements.

\section{RESEARCH MATERIAL AND METHODS}

In a multifactorial experiment the extremum problem solving is usually carried out by two methods: gradient one (ascent method) [5] and serial simplex planning [6]. Unfortunately, in the theory of experiment these methods are developed to optimize an objective function. As in $[7,8]$, for the multiobjective optimization of the response surface the function of desirability should be utilized:

$$
d=\left(d_{1}^{\Re_{1}} \cdot d_{2}^{\Re_{2}} \cdot \ldots \cdot d_{n}^{\Re_{n}}\right)=\left(\prod_{k=1}^{w} d_{k}^{\Re}\right)^{1 / \sum \Re},
$$

where $d$ is an integral (whole) function of desirability for all objective functions, included into process flow optimization; $d_{k}, k=\overline{1 ; w}$ - a differential function of desirability of $k$ objective function of $y_{k} ; \Re=\overline{1 ; 5}$ - ranks, assigned to the objective functions

For the computer search for differential functions of $d_{k}$ models I of multivariate analysis of dispersion (MDA) are used [9]. The optimization of every desired average response can be realized in the observation space by the following piecewise continuous functions depending on the set target:

a) minimum (Fig.1,a)

$$
\left.\begin{array}{ll}
d_{k}=1,0 & y_{k} \leq y_{k \min }, \\
d_{k}=\left[\frac{y_{k \max }-y_{k}}{y_{k \max }-y_{k \min }}\right]^{n} & y_{k \min }<y_{k}<y_{k \max }, \\
d_{k}=0,0 & y_{k} \geq y_{k \max } .
\end{array}\right\}
$$

b) maximum (Fig.1, $b$ ) 


$$
\left.\begin{array}{ll}
d_{k}=0,0 & y_{k} \leq y_{k \min }, \\
d_{k}=\left[\frac{y_{k}-y_{k \min }}{y_{k \max }-y_{k \min }}\right]^{n} & y_{k \min }<y_{k}<y_{k \max }, \\
d_{k}=1,0 & y_{k} \geq y_{k \max } ;
\end{array}\right\}
$$

$c$ ) the search for the set value of $t_{k}$ goal function ( $t$ - the initial letter of the word target), Fig.1, $c$

$$
\begin{array}{ll}
d_{k}=0,0 & y_{k} \leq y_{k \min }, \\
d_{k}=\left[\frac{y_{k}-y_{k \min }}{t_{k}-y_{k \min }}\right]^{n} & y_{k \min }<y_{k} \leq t_{k}, \\
d_{k}=1,0 & y_{k}=t_{k} ;
\end{array}
$$

or

$$
\begin{array}{ll}
d_{k}=0,0 & y_{k} \geq y_{k \max }, \\
d_{k}=\left[\frac{y_{k \max }-y_{k}}{y_{k \max }-t_{k}}\right]^{n} & t_{k}<y_{k}<y_{k \max } \\
d_{k}=1,0 & y_{k}=t_{k} ;
\end{array}
$$

d) free variation is in the range, Fig. $1, d$

$$
\left.\begin{array}{ll}
d_{k}=0,0 & y_{k} \leq y_{k \min }, \\
d_{k}=1,0 & y_{k \min }<y_{k}<y_{k \max } \\
d_{k}=0,0 & y_{k} \geq y_{k \max } .
\end{array}\right\}
$$

In (2)-(6) the following notations are agreed: $y_{k}-$ predictable average of $k$ objective function; $y_{k \min }, y_{k \max }-$ the smallest and largest observation, respectively, predicted in $U$ space of the studied objective function; $n$ - the index of weight function for $k$ piece perfection factor, the physical meaning is shown in Fig.1.

As may be inferred from Fig.1, when $n=1$ (curve 2), the search for the objective function optimum is carried out in $U_{1} \subset U$ subspace with linear regression. Decreasing $n$ to 0,1 (curve 1), $U_{1}$ subspace expands under simultaneous declining motion intensity to absolute optimum, that is defined by the greatest value of $d_{k}=1,0$. In case of choosing $n=10$ (curve 3 ), $U_{1}$ subspace decreases, however, the motion intensity to the optimum increases. On curves $1-3$, set by $U_{1} \subset U$ inequality, the system calculates and fills in desired coordinates $\left(y_{k}, d_{k}\right)$. For the optimization target of «range» (Fig.1, c), the line segment of $y_{k} \in\left[y_{k \min } ; y_{k \text { max }}\right]$ conforms $n=1$. In practice, function (5) is comfortably defined for the correlated output parameters.
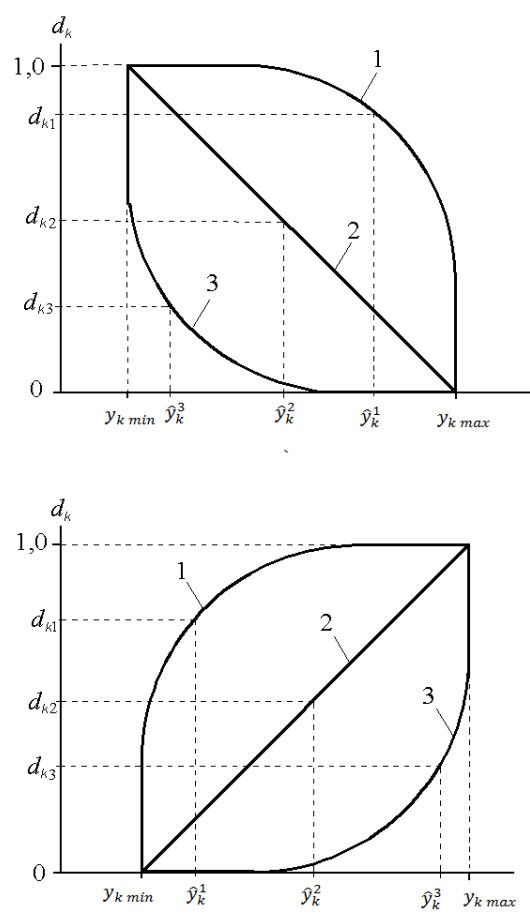

b)

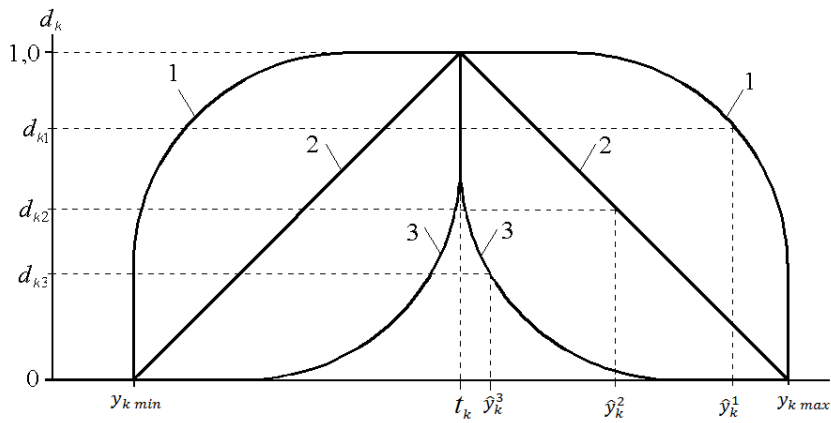

c)

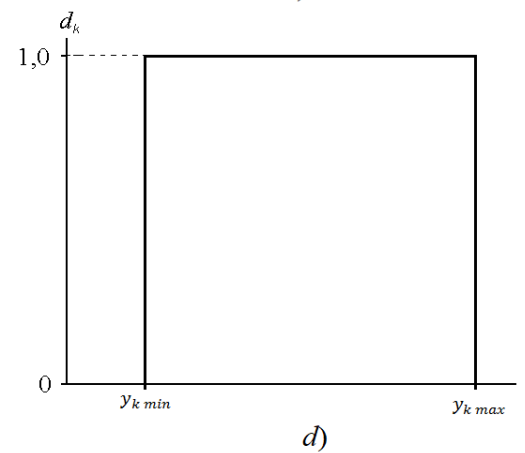

Fig. 1. The graphical interpretation of the optimization target and weight function

The objective function optimum search is conducted in $U_{1} \subset U$ subspace using linear regression. Setting the targets 
of optimization for independent variables can be developed by the following scripts:

1. Using «target», the average response approximation to the set target is not ideally supported and, then, leads to two independent problem solutions (4) and (5), from which the best one is chosen.

2. «Is equal to» makes it possible to strictly keep a set value of the response variable.

The realization of relations (1)-(6) was carried out with Stat-Ease Design-Expert 9.0.4.1 [9], that implements extremum seeking of the objective functions by simplex planning method. For the gradient motion the coordinates of vertexes of simplex of MDA model I are automatically calculated.

The experiments are performed under the following fixed conditions: working machine 3G71; wheels 1A1 $200 \times 20 \times 76 \times 5$ CBN 30 B151 100 O VK27 (Open Joint Stock Company, Scientific Industrial Complex «Abrasives and Grinding», Saint-Petersburg); ground surface - butt end of round billet of $D \times L=35 \times 40 \mathrm{~mm}$, cutting speed of $v_{\mathrm{K}}=28 \mathrm{~m} / \mathrm{sec}$; 5\% aqueous emulsion cutting coolant, Akvol-6 (TU 0258-02400148843-98), supplied by part irrigation in the amount of 7$10 \mathrm{l} / \mathrm{min}$.

Taking into account parts compliance to generate the surface condition, a variable rigidity framework tool was used. This made it possible to simulate the grinding action of variable rigidity parts, when fixed mass and size samples were mounted on the tool.

TABLE I. THE NATURAL AND NORMALIZED FACTORS OF CCRUD

\begin{tabular}{|c|c|c|c|c|c|}
\hline \multirow{2}{*}{$\begin{array}{c}\text { Factor } \\
\text { levels }\end{array}$} & \multicolumn{5}{|c|}{ Factors } \\
\cline { 2 - 6 } & $\begin{array}{c}f_{\mathrm{n}}, \mathrm{m} / \mathrm{min} \\
(A)\end{array}$ & $\begin{array}{c}f_{e}, \mathrm{~mm} / \text { double } \\
\text { stroke }(B)\end{array}$ & $\begin{array}{c}a_{p}, \mathrm{~mm} \\
(C)\end{array}$ & $\begin{array}{c}z, \mathrm{~mm} \\
(D)\end{array}$ & $\begin{array}{c}j, \mathrm{~N} / \mathrm{mm} \\
(E)\end{array}$ \\
\hline+1.81 & 10.0 & 6.00 & 0.025 & 0.300 & 11220 \\
\hline+1.00 & 8.2 & 4.50 & 0.020 & 0.255 & 7840 \\
\hline 0.00 & 6.0 & 3.00 & 0.015 & 0.200 & 5680 \\
\hline-1.00 & 3.8 & 1.75 & 0.010 & 0.145 & 2660 \\
\hline-1.81 & 2.0 & 0.50 & 0.005 & 0.100 & 380 \\
\hline $\begin{array}{l}\text { Note. } f_{\mathrm{n}} \text { - line feed; } f_{e} \text { - cross-feed; } a_{p} \text { - cutting depth; } z \text { - operational allowance; } \\
j \text { - compliance }\end{array}$
\end{tabular}

The system design was made with the help of the matrix of the central compositional rotatable uniform design (CCRUD). In the core, there was a complete factorial design of $2^{5}$ type (Table 1). The amount of different experiments in CCRUD resulted in $N=65$, considering repetitions of $m=3$, their total amount increased to 195 . The plan gives more precise mathematical formulation of the response surface. This can be achieved due to increasing the number of the experiments in the centre of the plan and a special choice of «stellar arm» $\alpha$.

The microrelief of the got surface is characterized by the following parameters (GOST 25142-82): Ra, Rz, Rmax, Sm. They were measured in two mutually orthogonal directions, coinciding with supply vectors $(g=1)$, and named: crosscut $R_{a 1}, R_{z 1}$ and etc. ( $\left.g=1\right)$ - c $f_{\mathrm{n}}$; longitudinal $R_{a 2}, R_{z 2}$ and etc. $(g=2)-\mathrm{c} f_{e}$. The macrogeometry of the flat surface was estimated at $E F E$ - flatness deviation during the grinding optimization.

\section{RESEARCH}

Using I MDA at 5\% confidence level, some models, partly shown in Table 2, were predicted. $R_{a 12}, S_{m 12}, R_{\max 2}$ models were got with the help of maximum likelihood method, $R_{\max 1}$, $R_{a 2}, \quad S_{m 2}, \quad p=\overline{10 ; 50 \%}, i, j=\overline{1 ; 2}$ were received by least square method [11].

TABLE II. I MDA MODELS IN 13X15H4AM3 CORROSION-RESISTANT PARTS GRINDING

\begin{tabular}{|c|c|}
\hline \multirow{2}{*}{$\begin{array}{c}\text { Param } \\
\text { eter }\end{array}$} & Regressions \\
\hline & $y, m k m$ \\
\hline$R_{a 1}$ & $\begin{array}{l}(1.23-0.11 A-0.18 B-0.036 C+0.067 D+0.18 E-0.030 A B+ \\
+0.029 A E-.028 C D+0.035 A^{2}+0.051 B^{2}+0.022 D^{2}+0.043 A B E- \\
-0.028 A D E-0.035 B D E+0.028 C D E+0.055 A^{2} B-0.043 A^{2} D- \\
\left.0.19 A^{2} E+0.068 A B^{2}\right)^{-1}\end{array}$ \\
\hline$R_{\max 1}$ & $\begin{array}{l}7.103+0.593 A+0.698 B-0.220 D-1.073 E_{2}-0.4374 A^{2}-0.315 B^{2}- \\
0.209 D^{2}-0.353 A^{2} B+0.961 A^{2} E-0.457 A B^{2}\end{array}$ \\
\hline$S_{m 1}$ & $\begin{array}{l}\left(0.027+0.000932 A-0.00184 B+0.000706 D+0.001 E_{2^{-}}\right. \\
0.0009 A B-0.0005 B E-0.0012 A^{2}-0.0009 C^{2}-0.00062 D^{2}- \\
\left.0.00146 E^{2}-0.0005 A C D-0.0018 A^{2} E\right)^{-1}\end{array}$ \\
\hline$R_{a 2}$ & $\begin{array}{l}0.411+0.033 B-0.036 E-0.026 A E-0.026 A^{2}- \\
0.022 A B E+0.050 A^{2} E+0.009 D^{3}\end{array}$ \\
\hline$R_{\max 2}$ & $\begin{array}{l}\left(0.55-0.017 A-0.019 B+0.036 A E+0.025 A^{2}-0.020 B C E-\right. \\
0.021 B D E)^{-2}\end{array}$ \\
\hline \multirow[t]{2}{*}{$S_{m 2}$} & $\begin{array}{l}272.325-16.308 C+27.927 C E+14.108 C^{2}-22.135 A C E- \\
31.573 A B^{2}+10.407 D^{3}\end{array}$ \\
\hline & $y, \mathrm{mkm}$ \\
\hline$t_{10(1)}$ & $1.482+0.133 B-0.197 D+0.258 A^{2} D$ \\
\hline$t_{20(1)}$ & $4.089+0.583 B$ \\
\hline$t_{30(1)}$ & $10.777+0.996 B-0.4438 D^{3}$ \\
\hline$t_{40(1)}$ & $23.533-0.77 D^{3}$ \\
\hline$t_{50(1)}$ & $42.72769+2.704167 A D+3.575 A E$ \\
\hline$t_{10(2)}$ & $0.902+0.132 C+0.116 B^{2}+0.180 B D E+0.1802 A B^{2}$ \\
\hline$t_{20(2)}$ & $\begin{array}{l}3.351-1.208 B-1.47558 D- \\
0.48015 A^{2}+1.031044 A^{2} B+1.838 A^{2} D\end{array}$ \\
\hline$t_{30(2)}$ & $7.910-1.528 B-2.702 D+1.676 A B-1.816 D E+2.764 A^{2} D$ \\
\hline$t_{40(2)}$ & 17.836 \\
\hline$t_{50(2)}$ & $40.142-6.821 D+7.042 A C E$ \\
\hline
\end{tabular}

The lack of orthogonality in CCRUD leads to the fact that estimated coefficients at linear effects and effects of their interactions ( $\mathrm{AB}, \mathrm{BC}, \mathrm{CD}$, etc.) are only uncorrelated with the rest members of regression, including an additive constant. Obviously, the insignificance of any other effects $\left(A^{2} D\right.$, $A^{2} E, C^{3}$ and etc.) inevitably results in the recalculation of the remainder of coefficients. This changes the precision of parametric estimators of the averages and error standards in every specific model. In this situation, during the optimization it is necessary not to only find the mode, permitting to keep the set-up output process parameters, but also the minimization of SDE error standards. 
$R_{\max }$ and $R_{a}$ parameters have the prevailing importance for the loaded parts of the aeronautical engineering, experiencing alternating loads. In this connection, to increase the reliability of the results of the robust design, the minimization of errors for roughness parameters $R_{a 1}$ and $R_{\max }$, measured in the crosscut direction relative to the wheel motion, was performed. Let us make two optimizations:

1. By parameters of micro- and macrogeometry with $\operatorname{SDE}(\mathrm{y})$ error minimization for the main roughness parameters such as $\mathrm{R}_{\mathrm{a} 12}$ and $\mathrm{R}_{\max 12}$. Optimization problem is $R_{\max 1} 8.0^{*}$ and $R_{a 1} 1.0^{*}$, TFE 9 where $\mathrm{z}=0,255 \mathrm{~mm}$. The received values should obey: $\quad R_{a 1} \in\left(0.8^{*} ; 0.1^{*}\right] ; \quad R_{\max 1} \in\left(6.3^{*} ; 8.0^{*}\right]$; $E F E \leq 40 \quad \mu \mathrm{m} \quad$ (TFE9): $\quad R_{a 1} \rightarrow$ target 1,$0 ; \quad S D E\left(R_{a 1}\right) \rightarrow$ minimum; $R_{\max 1} \rightarrow$ target $8.0 ; \quad S D E\left(R_{\max 1}\right) \rightarrow$ minimum; $R_{z} \rightarrow$ is rang $\left(R_{z 12} \in\left[\mathrm{y}_{k \text { max }} ; \mathrm{y}_{k \text { min }}\right]\right) ; t_{p} \rightarrow$ maximum, $p=\overline{10 ; 50 \%} ; E F L \rightarrow$ target 0.0.

2. By parameters of micro- and macrogeometry without $\operatorname{SDE}(y)$ error minimization, under the same other conditions.

Let us fix two parameters: $\mathrm{D}=+1(\mathrm{z}=0.255 \mathrm{~mm})$ and $\mathrm{E}=-$ $1.0(\mathrm{j}=2660 \mathrm{~N} / \mathrm{mm})$. Analyzing $\operatorname{SDE}\left(R_{\max 12}\right)=\mathrm{f}\left(f_{n} ; f_{e}\right)$ surface the system retrieved the absolute minimum point and found a solution, satisfying optimization tasks: $R_{\max 12} 8.0^{*}$ and $R_{a 12} 1.0^{*}$. The optimum points for both of the optimizations differ from each other, the obtained results of the optimization are given in Table 3.

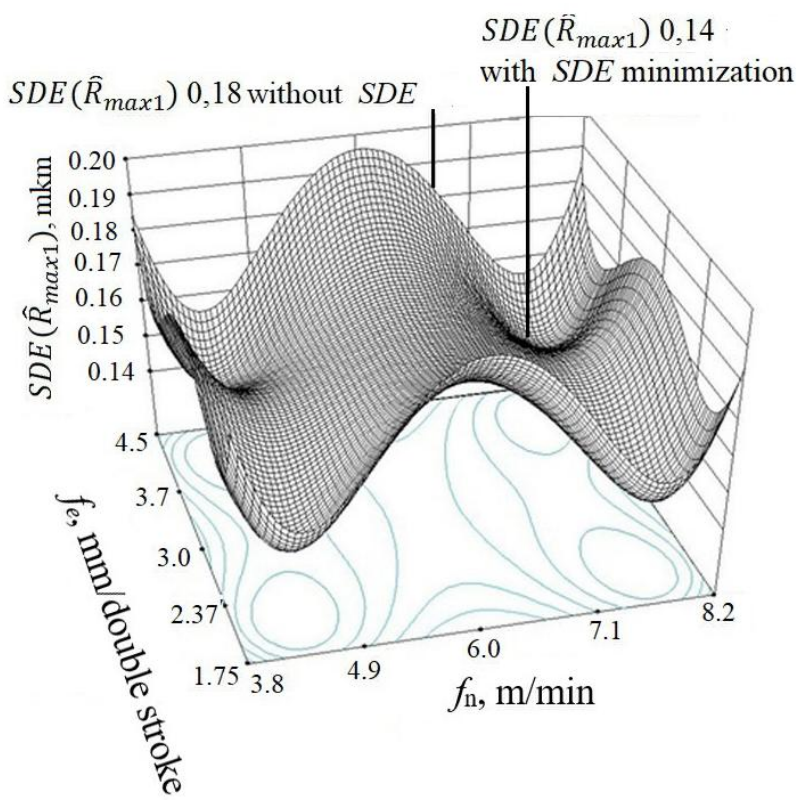

Fig. 2. The surfaces of error standards for $R_{\max 1}$ (experiment condition - see Table 2)
The surfaces of error standards (Fig.2) and average responses (Fig.3) with SDE and without it are shown for $\mathrm{R}_{\max 12}$. As Table 3 shows, the required parameters are ideally identified, however, rejecting the minimization of the error standards causes the increase of $\operatorname{SDE}\left(R_{a 1}\right)$ error standard from 0.025 to $0.04, \operatorname{SDE}\left(R_{\max 1}\right)$ from 0.14 to 0.18 that decreases the reliability of the obtained results. Nevertheless, this improves the process performance by reason of the crossfeed and cutting depth increase. The minimization of the error standards can be ignored in the situation, providing that all required parameters are identified with sufficiently large reserve, overlaying the error.

TABLE III. RESURSE OF 13X15H4AM3 STEEL LOW-RIGIDITY PARTS OPTIMIZATION ( $J=2660$ N/MM) UNDER CBN 30 B151 100 O VK27 (Z=0.255 MM) WHEEL GRINDING

\begin{tabular}{|c|c|c|c|}
\hline $\begin{array}{c}\text { Optimi } \\
\text { zation } \\
\text { type }\end{array}$ & $d$ & $\begin{array}{c}\text { Table } \\
\text { column } \\
\text { subhead }\end{array}$ & Predicted parameters \\
\hline 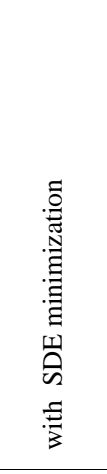 & $\begin{array}{l}8 \\
\text { D. } \\
0 \\
0\end{array}$ & 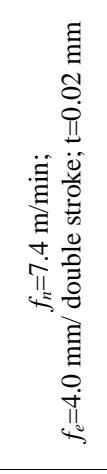 & 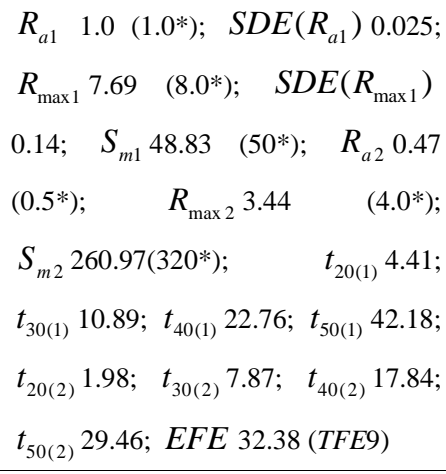 \\
\hline 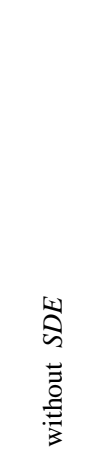 & $\begin{array}{l}0 \\
\infty \\
0 \\
0\end{array}$ & 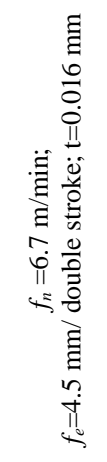 & $\begin{array}{c}R_{a 1} 1.0\left(1.0^{*}\right) ; \operatorname{SDE}\left(R_{a 1}\right) 0.04 ; \\
R_{\max 1} 8.0\left(8.0^{*}\right) ; \operatorname{SDE}\left(R_{\max 1}\right) \\
0.18 ; S_{m 1} 44 . .5\left(50^{*}\right) ; R_{a 2} 0.5 \\
\left(0.5^{*}\right) ; R_{\max 2} 3.44\left(4.0^{*}\right) ; \\
S_{m 2} 261.23\left(320^{*}\right) ; t_{20(1)} 4.67 ; \\
t_{30(1)} 11.32 ; t_{40(1)} 22.76 ; t_{50(1)} 42.45 ; \\
t_{20(2)} 0.92 ; t_{30(2)} 6.31 ; t_{40(2)} 17.84 ; \\
t_{50(2)} 32.48 ; E F E 30.33(T F E 9)\end{array}$ \\
\hline
\end{tabular}




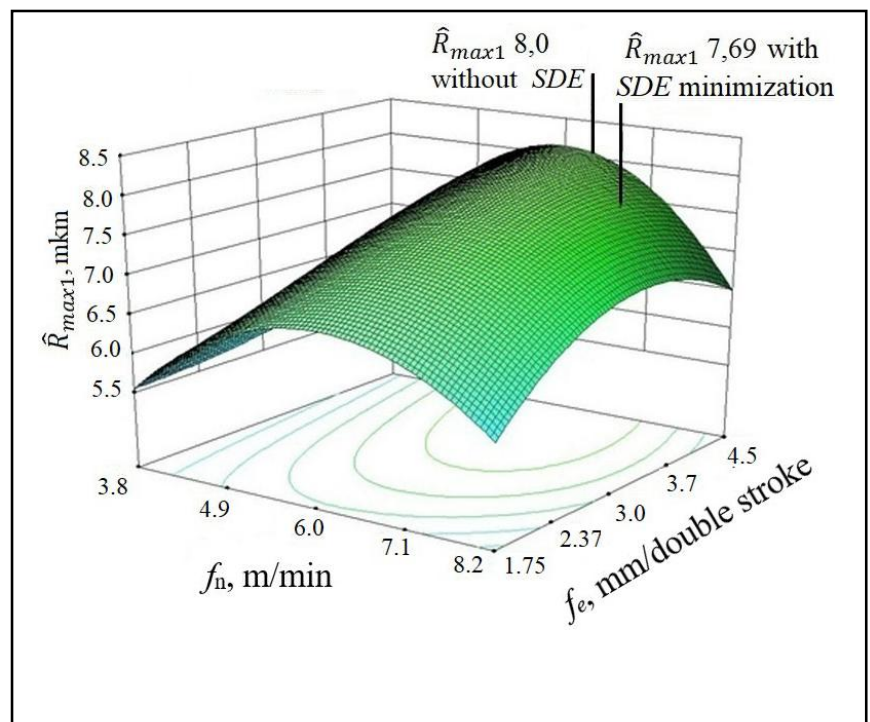

Fig. 3. The surfaces average response (b) for $\mathrm{R}_{\max 1}$ (experiment condition see Table 2)

\section{CONCLUSION}

The view of the significant model influences the precision of the parametric estimations of the averages and error standards, as the coefficient estimations at main effects and the first-order interaction effects are not correlated with other members of regression, including an additive constant. In that event, to increase the reliability of the prediction results, the optimization should be carried out with the minimization of SDE error standards. However, it can be neglected, if the required optimization parameters have a great reserve of dependability relative to the limiting value of categorial quantities.

\section{References}

[1] G. Taguchi, S. Chowdhury, Taguchi's Quality Engineering Handbook, ASI Consulting Group, LLC, Livonia, Michigan, 2005.

[2] Khosrow Dehnad, Quality Control, Robust Design, and the Taguchi Method, Pacific Grove, CA: Wadsworth \& Brooks/Cole, 1988.

[3] M. Ebrahimi, R. Whalley, "Analysis, modeling and simulation of stiffness in machine tool drivers," Computers \& Industrial Engineering, Vol. 38, pp. 93-105, 2000.

[4] A. Swic, W. Taranenko, "Adaptive control of machining accuracy of axial-symmetrical low-rigidity parts in elastic-deformable state," Eksploatacja i Niezawodnosc - Maintenance and Reliability, Vol. 14 (3), pp. 215-221, 2012.

[5] G.E.P. Box, K.B. Wilson, "On the experimental attainment of optimum conditions," Journal of Royal Statistical Society, Series B. V. XIII, Vol. 1 , pp. 1-45, 1951.

[6] W. Spendley, G. R. Hext, F. R. Himsworth, "Sequential Application of Simplex Designs in Optimization and Evolutionary Operation," Technometrics, Vol. 4, №4, pp. 441-461, 1962

[7] R.H. Myers, D.C. Montgomery, C.M. Anderson-Cook, Response Surface Methodology: process and product optimization using designed experiments, Wiley, 2016.

[8] G. Derringer, R. Suich, "Simultaneous Optimization of Several Response Variables," Journal of Quality Technology, Vol. 12, pp. 214219, 1980.

[9] Ya.I. Soler, Chi Kien Nguyen, "Modeling of the surface microrelief during multi-pass grinding of parts of varlable rigidity from alloy 1933T2," Journal of Fundamental and Applied Scienes, Vol. 9 (1(S)), pp. 1327-1340, 2017.

[10] I.D. Montgomery, Design and analysis of experiment, New Jersey, John Wiley \& Sons, 2012.

[11] K. Nadolny, W. Kaplonek, "Analysis of flatness deviations for austenitic stainless steel workpieces after efficient surface machining," Measurement science review, Vol. 14, No. 4, pp. 240-212, 2014.

[12] G. Eason, B. Noble, I.N. Sneddon, "On certain integrals of LipschitzHankel type involving products of Bessel functions," Phil. Trans. Roy. Soc. London, vol. A247, pp. 529-551, April 1955. 